\title{
Objective Structured Clinical Examination (OSCE); Strengths and Hurdles in Implementation
}

\author{
Muhammad Moin ${ }^{1}$ \\ ${ }^{1}$ Director Medical Education, Head of the Ophthalmology Department \\ Ameer-ud-Din Medical College, Postgraduate Medical Institute, Lahore
}

Objective structured clinical examination (OSCE) was established by Harden in 1975 to assess performance in a simulated environment within a specified time. ${ }^{1}$ There are many variations to this original technique. In Pakistan OSCE and later task oriented assessment of clinical skills (TOACS) was introduced by the College of Physicians and Surgeons (CPSP) in postgraduate examinations in 1990s and this was later implemented at the undergraduate level by Pakistan Medical and Dental Council as Objective Structured Practical Examination (OSPE). ${ }^{2}$ It has been used to assess wide range of topics including history, examination, radiological investigations, blood reports and counselling. Assessment methods in most of the postgraduate programs are designed to check the competence of students at the end of their training in the form of summative exit examinations. In the Miller's pyramid 'Knows' is typically checked by using MCQs while 'Knows how' is checked by case presentations and essays. OSPE on the other hand assesses the performance of the student at the 'shows how' level of the Miller's pyramid. 'Does' is checked by Work based assessments or Direct Observation of procedural skills. Most of the undergraduate and

How to Cite this Article: Moin $M$. Objective Structured Clinical Examination (OSCE); Strengths and Hurdles in Implementation. Pak $\mathrm{J}$ Ophthalmol. 2020; 36 (4): 312-314.

Doi: https://doi.org/10.36351/pjo.v36i4.1129

Correspondence: Muhammad Moin

Head of the Ophthalmology Department, Ameer-ud-Din Medical College, Postgraduate Medical Institute, Lahore

Email:mmoin7@gmail.com

Received: August 12, 2020

Accepted: September 14, 2020 postgraduate examinations assess their students up to the $3^{\text {rd }}$ level (shows how) as the feasibility to check the highest level (Does) is not good. ${ }^{3}$

Long and short case examination used to be the gold standard of assessment for a long time. The major drawback of this method was the subjectivity of the examination. Teachers had the power to pass or fail a student by assessing his performance on a few cases which did not cover majority of the topics in the specialty being examined. Students always felt that they were at the mercy of the bad examiners because of the poor inter rater reliability of this assessment method. ${ }^{4}$ OSCE was introduced to counter these weaknesses and now has become the new gold standard for assessing the clinical competence of students with a very high reliability of $0.91 .^{5}$ It is now used as a method to assess all the 3 domains of learning in addition to the long case and short case. It has two major underlying principles which include objectivity and structure. The objectivity depends upon standardization of the answering rubrics and trained examiners. Each station has a standardized design which assesses a specific clinical task which is blue printed against the curriculum. More centers are using standardized cases to further improve the objectivity of this method. These characteristics have shown that OSCE has very high validity and reliability which can assess all three domains of learning including cognition, skill and affect. ${ }^{6}$ Feasibility of OSPE has shown that it is more resource intensive as compared to other techniques of assessment. Organization of an OSCE is time consuming and when conducted in the recommended manner it incurs huge costs for the medical institutions. Engaging multiple trained examiners for all the stations is a difficult task as well. ${ }^{7}$ Proper examination stations are required to maintain confidentiality of each station. Usually $8-16$ stations are included with a time duration of 5 minutes for each station. Usually 70 to 160 minutes are 
required for one round of OSPE with multiple examiners at all the stations. ${ }^{8}$ Multiple stations allow assessment of performance in different areas of the specialty in a short period of time.

Mujumdar et al in a study of 52 final year students and 22 examiners found that majority of the students gave positive feedback about the OSCE examination held in their university in Trinidad. The attributes (fairness, structure, administration, sequence, structure and coverage of knowledge/skills), reliability, validity, organization (time table, announcements, room quality) were all rated well by the students. However, they felt that the environment was stressful and the difficulty level of some stations was difficult. Majority of the examiners were satisfied with the process, administration and organization of the OSPE examination. ${ }^{9}$ Khan et al conducted a study of 250 final year students at Khyber Medical College, Peshawar and found that the exam was found to be fair and comprehensive by $88 \%$ of the students, it was believed to be more stressful and tough mentally by 94\% students, it was felt to be reliable and valid by $96 \%$ of the students and it was found to be an appropriate examination to assess clinical competency by $87 \%$ of the students. ${ }^{2}$

In Pakistan there are many challenges in assurance of quality in Medical education. ${ }^{10}$ This has led to a decline in the quality of assessment using OSCE over the years. The International Association of Medical Education (AMEE) has published guidelines for organization and administration of OSCE. The objectives have been developed to elaborate the essential steps to ensure quality of OSCE. According to the guidelines the reliability is compromised if the coaching of standardized patients is deficient, examiners are not trained adequately, quality of questions and answering rubric are poor. The validity is also affected if the questions are not according to the learning outcomes and are unrealistic. ${ }^{11}$ Unfortunately examples of lapses in such quality assurance steps are seen in our system of Medical Education. These include the introduction of many static stations instead of interactive stations during this exam. These stations do not assess the performance but just the knowledge which can be assessed by using other techniques. Time duration of the stations is manipulated by the examiners reducing the reliability of the examination. Some places lack proper stations for OSPE thereby encouraging the students to get help from their colleagues. This happens due to short distances between stations without any visual barriers thereby allowing the students to easily visualize the answer sheets of their colleagues. In some institutions even short cases are included as some OSPE stations. These stations with short cases do not include a rubric thereby leading to reduced objectivity in the examination and inadequate assessment of the students due to shortage of time at each station. Answering rubrics used for OSPE do not have a penalty for the incorrect sequence of response from the students. This allows the student to give multiple responses incoherently but as they are included in the key the examiners have the leverageto mark the responsesas correct. Training of examiners is deficient in undergraduate examination due to the large number of examiners required by the universities. Simulated patients are an asset to the exam because they improve objectivity by giving the same response to the students all the time. Unfortunately, many institutions do not have a large pool of simulated patients. Question banking with Item analysis of each station is required to improve the quality of OSPE in each examination. ${ }^{12}$ Some institutions have this facility but it is lacking in other medical colleges.

OSCE is a valuable tool to assess performance of students in a simulated environment. ${ }^{13}$ We need to take necessary steps to improve the standards of OSCE in Pakistan by improving the validity, reliability, cost efficiency and acceptability of the test. The Universities conducting examination of multiple medical Colleges need to make sure that a central OSCE is developed rather than asking each institution to develop their own OSCE stations independently without any quality control. Training and certification of Assessors is an essential step in quality control. Use of trained simulated patients is becoming essential to check certain skills with high reliability. The validity can be improved by ensuring the blue printing of OSCE stations. All Institutions should develop dedicated examination halls to conduct OSCE for all specialties. This would reduce the burden on each specialty to develop stations in their department with compromised facilities. Feedback from students, examiners and patients' needs to be taken to continuously improve the stations every year. It has been shown that students pass the examination even if they do not know certain essential skills asked at a station because of compensation from other stations. This reduces the assessment of competency of the students. Therefore, passing the stations having 
essential skill assessment should be made compulsory in all OSCE.Realization of these realities about OSCE in our country is essential and we should strive to bring it to international standards.

\section{REFERENCES}

1. Harden RM, Stevenson M, Downie WW, Wilson GM. Assessment of clinical competence using objective structured examination. Br Med J. 1975; 1: 447-451. Doi:10.1136/bmj.1.5955.447.

2. Khan A, Ayub M, Shah Z. An audit of the medical students' perceptions regarding objective structured clinical examination. Educ Res Int. 2016: Article ID 4806398:4. Doi: 10.1155/2016/4806398.

3. Khan KZ, Ramachandran S, Gaunt K, Pushkar P. The objective structured clinical exam (OSCE): AMEE guide no. 81-part I: an historical and theoretical perspective. Med Teach. 2013; 35 (9): e1437- e1446. Doi: 10.3109/0142159X.2013.818634.

4. Troncon LEA, Dantas RO, Figueiredo JFC, Ferriolli E, Moriguti JC, Martinelli ALC, et al. A standardized, structured long-case examination of clinical competence of senior medical students, Medical Teacher, 2000; 22 (4): 380-385. Doi: 10.1080/014215900409483.

5. Sloan D, Donnelly MB, Schwartz R, Strodel W. The objective structured clinical examination - the new gold standard for evaluating postgraduate clinical performance. Ann Surg. 1995; 222 (6): 735-742.

6. Moeen-Uz-Zafar A, Shammari O, Aljarallah B. Evaluation of interactive OSCE for medical students in the subject of medicine; reliability and validity in the setting of internal vs. external examiners. Ann Public Health Res. 2015; 2 (4): 1030.
7. Harden RM. Misconceptions and the OSCE. Med Teach. 2015; 37 (7): 608-610. Doi: 10.3109/0142159X.2015.1042443.

8. Heal C, D'Souza K, Banks J, Malau-Aduli BS, Turner R, Smith J et al. A snapshot of current Objective Structured Clinical Examination (OSCE) practice at Australian medical schools, Medical Teacher, 2019; 41 (4): 441-447. Doi: 10.1080/0142159X.2018.1487547.

9. Mujumdar MAA, Kumar A, Krishnamurthy K, Ojeh N, Adams OP, Sa B. An evaluative study of objective structured clinical examination (OSCE): students and examiners perspectives. Adv Med Educ Pract. 2019; 10: 387-397. Doi: 10.2147/AMEP.S197275.

10. Khan AW, Sethi A, Wajid G, Yasmeen R. Challenges towards quality assurance of Basic Medical Education in Pakistan. Pak J Med Sci. 2020; 36 (2): 4-9. Doi: https://doi.org/10.12669/pjms.36.2.1319.

11. Khan KZ, Gaunt K, Ramachandran S, Pushkar P. The Objective Structured Clinical Examination (OSCE): AMEE Guide No. 81. Part II: Organisation\& Administration, Medical Teacher, 2013; 35 (9):e1447e1463, Doi: 10.3109/0142159X.2013.818635.

12. Pell G, Fuller R, Homer M, Roberts T. How to measure the quality of the OSCE: A review of metrics AMEE Guide No. 49, Medical Teacher, 2010; 32 (10): 802-811. Doi: 10.3109/0142159X.2010.507716.

13. Gormley G. Summative OSCEs in undergraduate medical education. Ulster Med J. 2011; 80 (3): 127-32. 